\title{
The Properties of Solvent-Based and Water-Borne Butyl Acrylate/Styrene Copolymer Films
}

\author{
Yi Wang (iD) and Zhonghua Chen \\ School of Materials Science and Engineering, South China University of Technology, Guangzhou, Guangdong, China \\ Correspondence should be addressed to Yi Wang; wyicslg@163.com
}

Received 24 February 2019; Revised 11 April 2019; Accepted 23 May 2019; Published 25 June 2019

Academic Editor: Liqun Zhang

Copyright ( 2019 Yi Wang and Zhonghua Chen. This is an open access article distributed under the Creative Commons Attribution License, which permits unrestricted use, distribution, and reproduction in any medium, provided the original work is properly cited.

\begin{abstract}
With the increasing demands of environmental protection, the properties of water-borne coatings film must meet or exceed current solvent-based coatings. It is an important part of coating science for characterizing the film properties of polymers which was used in the water-borne and the solvent-based coating. In this study, UV-visible spectroscopy, gravimetric analysis, scanning electron microscopy, and electrochemical impedance spectroscopy were used to characterize the properties of the water-borne and the solvent-based poly(butyl acrylate/styrene) $(\mathrm{P}(\mathrm{BA} / \mathrm{St}))$ copolymer films. The water-borne and the solvent-based $\mathrm{P}(\mathrm{BA} / \mathrm{St})$ copolymer was synthesized by two methods. The copolymer had a Tg of approximately $14.4^{\circ} \mathrm{C}$, which was close to room temperature. The waterborne copolymers were prepared via a three-step film formation process, while the solvent-based copolymer films were prepared in two steps. Comparing the properties of the water-borne and the solvent-based films, the water absorption capacities decreased with increasing film formation times, and the film barrier properties and electrochemical properties of both films improved as the film formation time increased.
\end{abstract}

\section{Introduction}

With the increasing demands of environmental protection, solvent-based coatings would be limited in various fields. Water-borne coatings were environmentally friendly coating. However, the water-borne coatings were not as good as the solvent-based coatings when used in exterior coatings, household varnishes, and wall paints. How to make the performance of water-borne coatings exceed that of the solvent-based coatings had become a hot issue in current research. It is very important to understand the film formation mechanisms of the solvent-based or the water-borne coatings to achieve this objective $[1,2]$. The coating film formation process was turned a polymeric dispersion into a continuous polymer film [3]. The film-forming process of the solvent-based coatings included two stages: bulk solvent evaporation (I) and diffusive solvent evaporation (II). During stage I of film-forming process, the polymer chains began to entangle into a tight network and eventually produced a solid film, and the solvent drying rate was high, and approximately 90\% (by mass) of the solvent was evaporated. The remaining solvent slowly evaporated over a longer period during stage II because of the tighter polymer network formed during stage I [4].

The film formation process for water-borne coatings could be divided into three major sequential steps $[5,6]$. Stage I was water evaporation: evaporation of the water brought the latex polymer particles into close contact. Stage II was particle deformation: the latex particles deformed and formed a voidfree solid structure; during this stage, the film was usually mechanically weak [7]. Stage III was latex coalescence: the polymer molecules diffused across the particle boundaries and created entanglements that made the films mechanical strength [8-10]. The particle deformation mechanism in the film formation process of water-borne coatings played an important role in defining the final film microstructure and properties of the film, including flexibility and strength [11]. The techniques that were used to study the water evaporation stage included the minimum film-forming temperature (MFFT) [12], gravimetry methods (GMM) [13], cryogenic scanning electron microscopy (CSEM) [14], and environmental scanning electron microscopy (ESEM) [15]. Contact atomic force microscopy (AFM) [16], transmission electron microscopy (TEM) [17], and scanning electron microscopy 
(SEM) [18] were usually used to study the latex particle deformation or packing stage. Small-angle neutron scattering (SANS) [19], fluorescence resonance energy transfer (FRET) [20], and transmission spectrophotometry [21] were often used to study the latex film coalescence or interdiffusion stage.

The Routh and Russel model showed that the deformation mechanisms of the latex particles could be different possible mechanisms depending on two dimensionless parameters, $\mathrm{Pe}$ and $\bar{\lambda}$. The parameter $\bar{\lambda}$ was defined as the ratio between the time needed for film compaction (for complete particle deformation, $\left.t_{d e f}\right)$ and the characteristic time for the evaporation of water, $t_{\text {evap }}$. This parameter could be written as follows:

$$
\bar{\lambda}=\frac{t_{\text {def }}}{t_{\text {evap }}}=\frac{\eta_{0} \mathrm{R}_{0} \mathrm{E}}{\gamma_{\mathrm{wa}} \mathrm{H}}
$$

where $\eta_{0}$ was the low shear viscosity of the polymer, $\gamma_{w a}$ was the water-air surface tension, $E$ was the evaporation rate, $H$ was the initial film thickness, and $R_{0}$ was the particle size. The parameter $P e$ was defined as the ratio between the characteristic time for the diffusion of the polymer particles from the top to the bottom of the film $\left(t_{\text {diff }}\right)$ and the evaporation time $\left(t_{\text {evap }}\right)$, and $P e$ could be written as follows:

$$
\mathrm{Pe}=\frac{6 \pi \mu \mathrm{R}_{0} \mathrm{HE}}{\mathrm{kT}}
$$

where $k$ was the Boltzmann constant, $\mathrm{T}$ was the temperature (K) during the film formation process, and $\mu$ was the viscosity of a spherical coating particle in the fluid. The particle deformation mechanisms were classified as wet sintering, capillary deformation, dry sintering, and Sheetz deformation [22-24].

During the drying of a water-borne coating, there was an incompatibility between the surfactant and the polymer; a parabolic distribution of the surfactant throughout the film could be seen. By measuring the particle interference in rewetted water-borne coating films, it could be obtained information regarding the particle deformation and the amount of absorbed water [25, 26]. Electrochemical impedance spectroscopy (EIS) measurements could show the particular protection behaviour of the coatings, i.e., an increase in the film resistance with immersion time. This was attributed to coalescence activated by the immersion of the film in a harsh solution [27]. In the film formation process, EIS could also be used to monitor the polymer film coalescence process, and the resistance of the film would increase with increasing film formation time [28, 29].

The main aim of this study was to investigate the filmforming processes for the solvent-based and the waterborne $\mathrm{P}(\mathrm{BA} / \mathrm{St})$ copolymers with the same composition. Gravimetric methods were used to study the water and solvent evaporation rates, and AFM and SEM were used to observe the microstructures of the films. In addition, the water absorption capacities and EIS data of the films formed by the two methods were determined to compare their film properties.

\section{Experimental}

2.1. Materials. Styrene (St), acrylic acid (AA), and butyl acrylate (BA) monomers were used as-received from Tianjing Fuyu Agent Co. (China) without further purification. Sodium dodecyl sulfate (SDS, Sigma-Aldrich Chemistry Co., China) was used as an emulsifier, azobisisobutyronitrile (AIBN, Sigma-Aldrich Chemistry Co., China) and potassium persulfate (KPS, Sigma-Aldrich Chemistry Co., China) were used as initiators, and sodium bicarbonate and ammonia were used as buffer agents. Methylbenzene was used as-received from Tianjing Fuyu Agent Co. (China). Doubly deionized (DDI) water was used for the water-borne $\mathrm{P}(\mathrm{BA} / \mathrm{St})$ copolymer.

\subsection{The Preparation of Solvent-Based and Water-Borne} $\mathrm{P}(\mathrm{BA} / \mathrm{St})$ Copolymers. The water-borne $\mathrm{P}(\mathrm{BA} / \mathrm{St})$ copolymer was synthesized by seeded semicontinuous emulsion polymerization. First, the emulsifier and monomers, as listed in Table 1, were dissolved in water in a $500 \mathrm{ml}$ flask, and the monomer was emulsified for $1 \mathrm{~h}$ with stirring. Second, $20 \%$ (by mass) of the monomer emulsion was added to a $500 \mathrm{ml}$ four-necked flask that was equipped with a reflux condenser, a nitrogen inlet, a sampling device, a tetrafluoroethylenecoated anchor stirrer rotating at $250 \mathrm{rpm}$, and a cascade temperature control system. The monomer emulsion was heated to $70^{\circ} \mathrm{C}$, and $50 \%$ (by mass) of the initiator was added. Third, when the emulsion turned blue, the temperature was raised to $80^{\circ} \mathrm{C}$, and the remaining monomer emulsion and initiator were added over a $2 \mathrm{~h}$ period. Once the addition was complete, the temperature was held at $90^{\circ} \mathrm{C}$ for $30 \mathrm{~min}$. Finally, the latex was cooled to room temperature, and the $\mathrm{pH}$ was adjusted to $8-9$. The $\mathrm{P}(\mathrm{BA} / \mathrm{St})$ latex was stored at room temperature.

The composition of the solvent-based $\mathrm{P}(\mathrm{BA} / \mathrm{St})$ copolymer synthesized by the solution polymerization was also shown in Table 1 . The polymerization was conducted in a $500 \mathrm{ml}$ four-necked flask that was equipped similarly to what was used for the water-borne solution with continuous stirring. The initiator (AIBN) was dissolved in methylbenzene, and the monomer was added over a $2 \mathrm{~h}$ period while the temperature was held at $80^{\circ} \mathrm{C}$. The temperature was held for another $30 \mathrm{~min}$ after the addition was complete.

\subsection{Physical Characterization of the $P(B A / S t)$ Copolymers [30]}

Solid Content. The initial weight and final weight of the solvent-based or water-borne $\mathrm{P}(\mathrm{BA} / \mathrm{St})$ copolymers were dried at $120^{\circ} \mathrm{C}$. The percentage of nonvolatiles (nv.\%) was determined as follows:

$$
n v . \%=\frac{\text { final weight }}{\text { initial weight }} \times 100 \%
$$

The samples were cooled to room temperature before reweighing in order to minimize the error in this measurement. The results were listed in Table 2.

Particle Size Determination. The particle Z-Ave size distribution of the water-borne $\mathrm{P}(\mathrm{BA} / \mathrm{St})$ was determined by a 
TABLE 1: The formulae of the solvent-based and water-borne $\mathrm{P}(\mathrm{BA} / \mathrm{St})$ copolymers.

\begin{tabular}{lccccccccc}
\hline & BA & St & AA & Water & Methylbenzene & KPS & AIBN & SDS $^{\text {NaHCO }_{3}}$ \\
\hline solvent-based (g) & 22 & 27 & 1 & - & 75 & - & 0.25 & 1 \\
water-borne (g) & 22 & 27 & 1 & 75 & - & 0.25 & - & 1 & 1 \\
\hline
\end{tabular}

TABLE 2: Properties of the $\mathrm{P}(\mathrm{BA} / \mathrm{St})$ copolymer.

\begin{tabular}{lcccc}
\hline & Solid Content $(\mathrm{nv} . \%)$ & $\mathrm{Tg}\left({ }^{\circ} \mathrm{C}\right)$ & Molecular weight $* \mathrm{M}_{\mathrm{w}}(\mathrm{g} / \mathrm{mol})$ & Z-Ave $(\mathrm{nm})$ \\
\hline water-borne & 38.9 & 14.4 & 45000 & 211.0 \\
solvent-based & 38.5 & 12.1 & 47000 & - \\
\hline
\end{tabular}

* PSt equivalent.

Malvern laser particle size analyser (LPSA, Malvern Instrument Co., Ltd., UK). The results were listed in Table 2.

Glass Transition Temperature (Tg). DSC measurements were performed using a DSC (201 FC, NETZSCH Group, German) with a temperature scanning range of 243 to $373 \mathrm{~K}$ at $10 \mathrm{~K} / \mathrm{min}$ using a sensitivity range of $5 \mathrm{mcal} / \mathrm{s}$. The scans obtained were used to determine the Tg. The results were listed in Table 2.

Molecular Mass Determination. Gel permeation chromatography (GPC) of the samples, performed by a gel permeation chromatography instrument (RAPRA Technology Ltd. German), involved dissolution of $20 \mathrm{mg}$ of a sample in $10 \mathrm{ml}$ of dimethyl formamide (DMF) and allowing the material to dissolve overnight. A Plgel $2 \mathrm{X}$ mixed bed, $30 \mathrm{~cm}, 10 \mathrm{~mm}$ column was used. DMF buffered with ammonium acetate as a flow rate of $1 \mathrm{ml} / \mathrm{min}$ was used as the eluent. The GPC system was calibrated with polystyrene (PSt). The results were reported as "PSt equivalent" molecular masses (Table 2).

Gravimetric Analysis. Water-borne and solvent-based $\mathrm{P}(\mathrm{BA} / \mathrm{St})$ copolymer films were prepared using an adjustable micrometre film applicator (Hangzhou Annuo Filter Equipment Co., Ltd. China) at an appropriate wet thickness to produce a dry film thickness of $50 \mu \mathrm{m}$. A Mettler AE260 Deltarange analytical balance (METTLER TOLEDO Instruments (Shanghai) Co., Ltd. China) was used to record mass changes to $0.0001 \mathrm{~g}$, the instrument sensitivity limit. The initial masses as well as any changes in the masses of the copolymer films for different film formation times and different film formation temperatures were recorded. The water-borne copolymer film formation temperature was $2^{\circ} \mathrm{C}$, $20^{\circ} \mathrm{C}, 25^{\circ} \mathrm{C}, 30^{\circ} \mathrm{C}$, and $35^{\circ} \mathrm{C}$. The solvent-based copolymer film formation temperature was $20^{\circ} \mathrm{C}, 30^{\circ} \mathrm{C}$, and $40^{\circ} \mathrm{C}$.

Atomic Force Microscopy (AFM). A Topo Metrix TMX 2000 atomic force microscope (Switzerland) was used to scan the films under ambient conditions in tapping mode.

Scanning Electron Microscopy (SEM). SEM was carried out using a field emission scanning electron microscope (Nova Nanosem 430, FEI Co., Netherlands) to investigate the surface of the latex films. All samples were coated with gold before SEM observation.
Water Absorption. Several films were prepared with the same film thickness but different film formation times at $25^{\circ} \mathrm{C}$ and atmospheric pressure and drying under similar conditions. Then, circular samples with diameters of $25 \mathrm{~mm}$ were immersed in deionized water. Their swelling behaviour was recorded by gravimetric measurements of the water absorption at the same time intervals [23].

Electrochemical Impedance Spectroscopy (EIS). EIS measurements were conducted with Corrtest CS310 software by using a CS2350H Electrochemical workstation (Wuhan Corrtest Instruments Corp., Ltd., China). EIS measurements were performed with a standard three-electrode cell set-up; a glass cell filled with $3 \% \mathrm{NaCl}$ clamped to a coated ion panel served as the working electrode. A saturated calomel reference electrode and graphite counter electrode were immersed in the electrode solution with $4 \mathrm{~cm}$ between the counter and working electrodes. An area of exposure of the working electrode equal to $14.6 \mathrm{~cm}^{2}$ was used for analysis from $1 \mathrm{MHz}$ to $0.01 \mathrm{~Hz}$ with an AC voltage of $20 \mathrm{mV}_{\mathrm{rms}}$ and a DC voltage of $0.0 \mathrm{~V}$ versus the open circuit potential of $-200 \pm 80 \mathrm{mV}$. The average potentiostat instrument error was ranged from $3 \%$ at low frequencies to less than $0.5 \%$ at high frequencies.

\section{Results and Discussion}

3.1. Properties of the $P(B A / S t)$ Copolymer. Table 2 showed the water-borne and the solvent-based $\mathrm{P}(\mathrm{BA} / \mathrm{St})$ copolymers in the two systems had similar properties. The water-borne $\mathrm{P}(\mathrm{BA} / \mathrm{St})$ copolymer could be used in latex coating systems.

3.2. The Film Formation Process of the Water-Borne $P(B A / S t)$ Copolymer. The water evaporation rate during the latex film formation process of the water-borne copolymer was studied by gravimetric analysis. The copolymer particles deformation mechanism was calculated by the Routh and Russel film deformation model [22-24]. The particles remain in water for the wet sintering mechanism. The particles deformation must be quickly enough so that no capillary pressure was established. In dry sintering, the particles were assumed to without significant deformation until the water had evaporated. The dry sintering condition was the deformation achieved by the 
capillary stress as the water evaporation was minimal [23]. The results were shown in Table 3 .

Figure 1 showed the water evaporation rates (the slopes) from the beginning of the film formation process of $\mathrm{P}(\mathrm{BA} / \mathrm{St})$ latex under different temperatures. For the water-borne $\mathrm{P}(\mathrm{BA} / \mathrm{St})$ copolymer, the water evaporation rate of the waterborne $\mathrm{P}(\mathrm{BA} / \mathrm{St})$ film formation had initially decreasing rate and then a linear rate and finally reached a near zero rate, as shown in Figure 1 for the film formed at $30^{\circ} \mathrm{C}$. At the beginning, the surface of the film was wet, and the water in the film could easily diffuse to the surface and evaporate into the air. When the drying rate was constant, the film surface did not remain wet because the water migration rate was less than the vaporization rate. The drying rate decreased gradually during film formation. In the final drying period, the mass transfer became difficult, and the drying rate gradually decreased to zero. Figure 1 also showed that the water evaporation rates increased with the film formation temperature. The water evaporation caused the voids between the latex particles to decrease, and particle fusion could increase the transparency of the latex film. It was clearly shown in Figure 2 that when the film was formed at $20^{\circ} \mathrm{C}$, the particles undergo a three-stage film formation process: the spherical, hexagonal, and partially cross-linked stages (polymer molecular diffused from one particle to another). According to the Russell-Routh model, the deformation mechanism was wetting sintering. During the sintering of the latex particles, not all of the water was evaporated. The calculated parameters shown in Table 3 also show this trend. There was a second phase where the water surrounded the particles. Images B and D in Figure 2 showed the particle coalescence had occurred.

3.3. The Film Formation Process for the Solvent-Based $P(B A / S t)$ Copolymer. Figure 3 showed the solvent evaporation rate (the slopes) of the solvent-based $\mathrm{P}(\mathrm{BA} / \mathrm{St})$ copolymer during film formation at three different temperatures. The process could be divided into two steps: a high linear evaporation rate and then a low decreasing rate. In the beginning, the films were full of solvent, which readily evaporated into the air. Then, the solvent content in the film was decreased, and the solvent evaporation rate decreased.

For the water-borne copolymers to completely replace the solvent-based copolymers in coating applications in the future, the postapplication film formation process must be improved. In this study, the copolymer had a Tg of approximately $14.4^{\circ} \mathrm{C}$, which was close to room temperature. The film formation processes for such copolymers were shown in Figure 4. For the water-borne copolymer, when the Tg of the copolymer was below the film formation temperature, the film formation process involved three steps. In the beginning, the water evaporated and the copolymer particles partially deform to generate a compact film filled with water. Then, with more water evaporates, all of the particles deformed and coalesced to yield a void-free film. After the water fully evaporated, the copolymer molecules diffused to afford a uniform film. For the solvent-based copolymer with a similar chemical structure, the film formation process was a solvent evaporation process. The solvent evaporation rate could be divided into two steps. During this process, the copolymers diffused in the final step to yield a uniform film.

3.4. Effect of Formation Time on the Rewetting Water Absorption of the Films. Figure 5 showed the water absorption capacities of the water-borne and the solvent-based $\mathrm{P}(\mathrm{BA} / \mathrm{St})$ copolymer films with different times while being rewet with deionized water. For the water-borne copolymer films, the weight of the film increased during the water absorption experiment. Moreover, at the beginning of the experiment, the magnitude of the increases in the masses of all films seemed to be equal, because water soluble substances in films, such as the emulsifier, dissolved, which caused creased voids that were quickly filled by water. The latex films had similar compositions, so those films gained a similar mass in this stage. However, after approximately $10 \mathrm{~h}$, the weight increases of each film were significantly different, and the longer the film formation time, the less the water absorbed. The films becoming compacted during the longer film formation processes, as shown in the microstructures (Figure 6). The W2h sample in Figure 6 was the dried film that was formed in an open container from the water-borne copolymer solution as shown for $2 \mathrm{~h}$; it had many voids in its microstructure. However, for the solvent-based copolymer film, the water absorption capacities for films prepared with different film formation times also increased with increasing time. Initially, the water quickly combined with the copolymer in the film, and very few voids formed in the films. As shown in the microstructures of S-2h to S-24h (Figure 6), the increase in weight was due to the water until an equilibrium reached. Comparing the water-borne and the solvent-based films, the water absorption capacities decreased with increasing film formation times for both types of films. However, for film formation times below $8 \mathrm{~h}$, the water-borne film absorbed more water than the solvent-based film because the waterborne film had more voids. Then, for film formation times over $8 \mathrm{~h}$, the two films absorbed almost the same mass of water, and the water-borne films became compact similar to the solvent-based films, as shown in Figure 6, W-8h, W-24h, and S-24h.

3.5. Effect of Formation Time on the Electrical Impedance of the Films. Electrical impedance analysis was used to elucidate the properties of the two types of polymer films. This technique provided spectra of the electrical impedance of the polymer films and their resistance or impedance barrier properties. The electrochemical changes in the waterborne and the solvent-based $\mathrm{P}(\mathrm{BA} / \mathrm{St})$ copolymer films were measured by impedance spectroscopy. The test was started when the weight of the film was constant, as showed in Figures 1 and 3. The film thickness was approximately $50 \mu \mathrm{m}$. Figure 7 showed the EIS Bode plots of the films with different film formation time.

For the water-borne copolymer films, the EIS spectra showed that the films resistance and barrier properties increased with film formation time. The barrier properties of the films were relatively poor in the first $0.5 \mathrm{~h}$ because the 


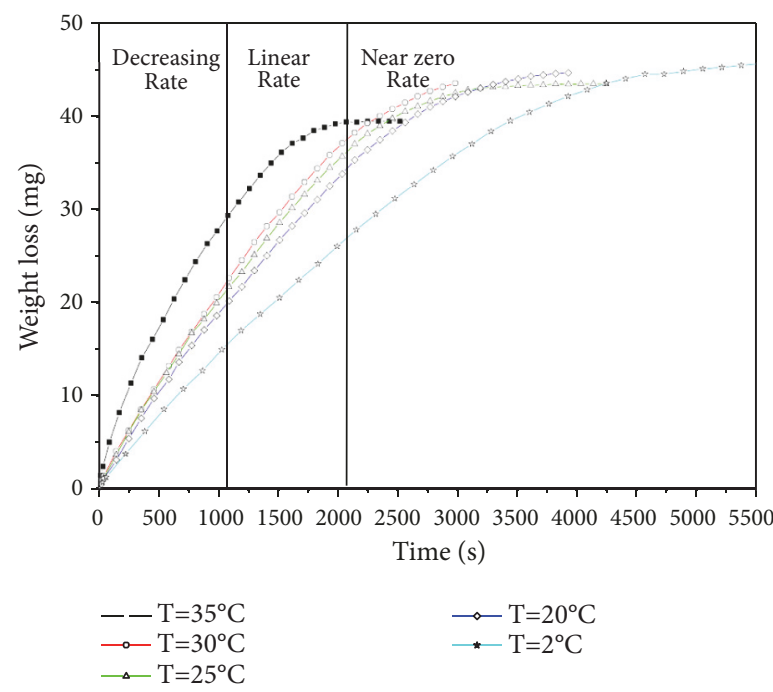

FIGURE 1: The water evaporation progress at different film formation temperatures.

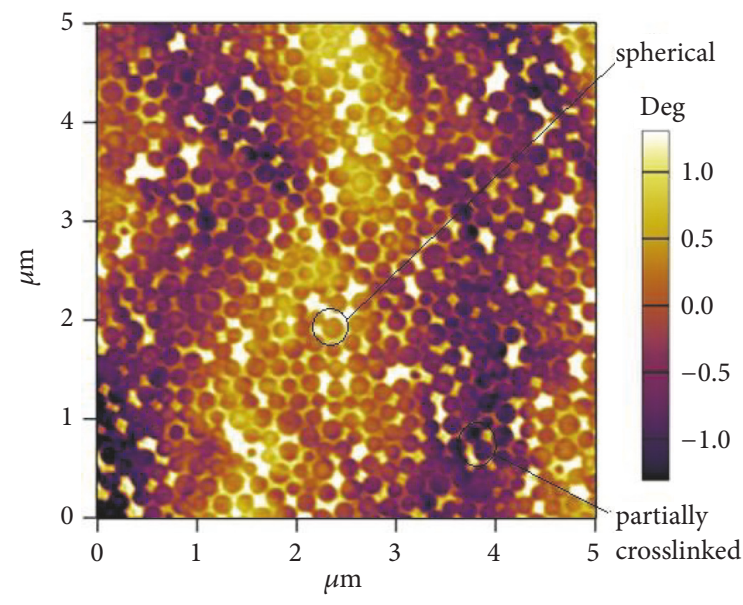

(a)

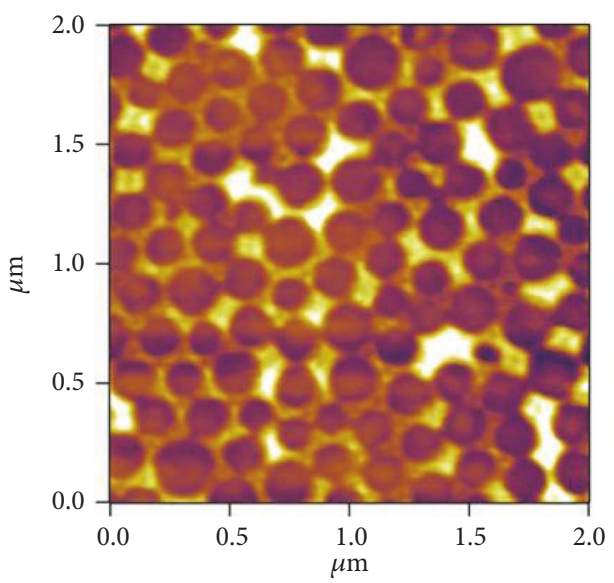

(c)

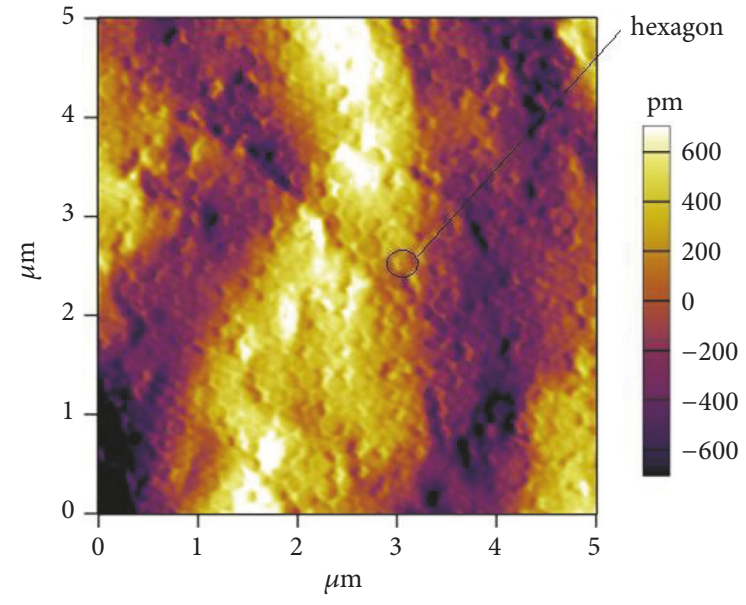

(b)

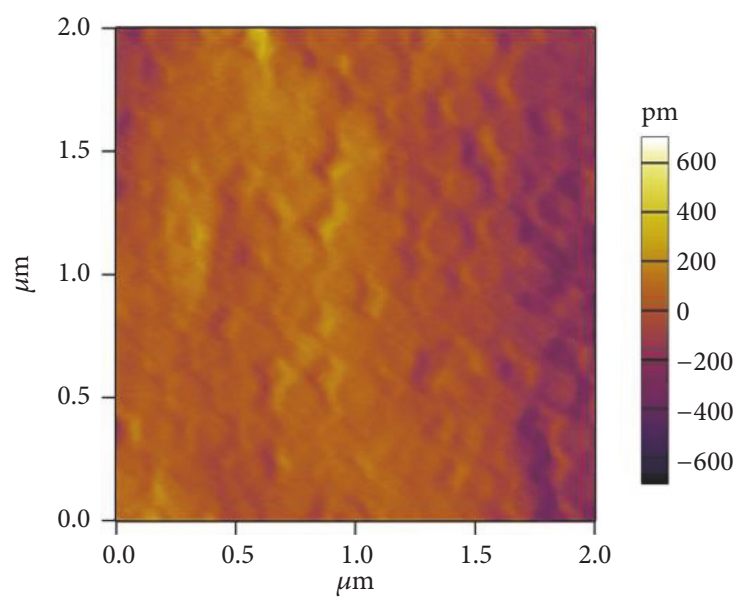

(d)

Figure 2: AFM images of a water-borne film after $20 \mathrm{~min}$ and film formation at $25^{\circ} \mathrm{C}$ ((a) and (c) for horizontal; (b) and (d) for vertical). 


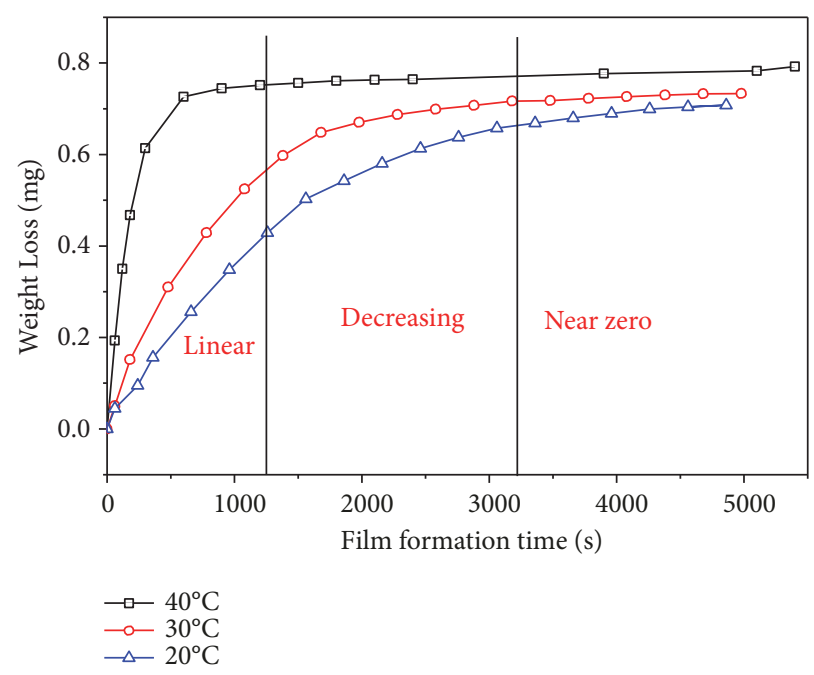

FIGURE 3: The solvent evaporation process at different film formation temperatures.

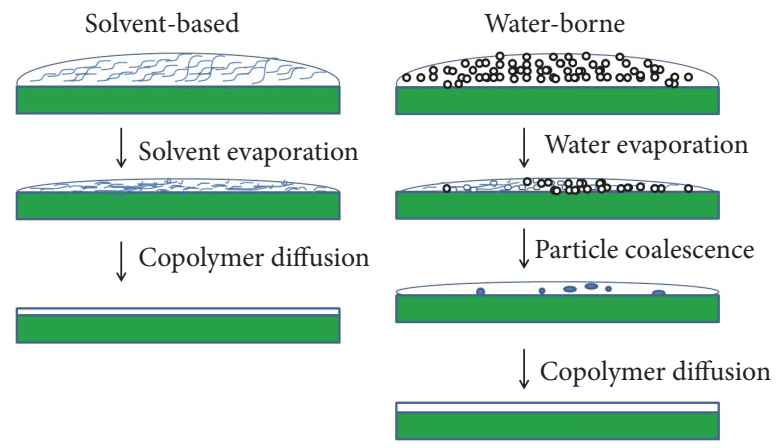

FIGURE 4: The film formation processes at room temperature for the solvent-based and the water-borne copolymers with Tg of approximately $14.4^{\circ} \mathrm{C}$.
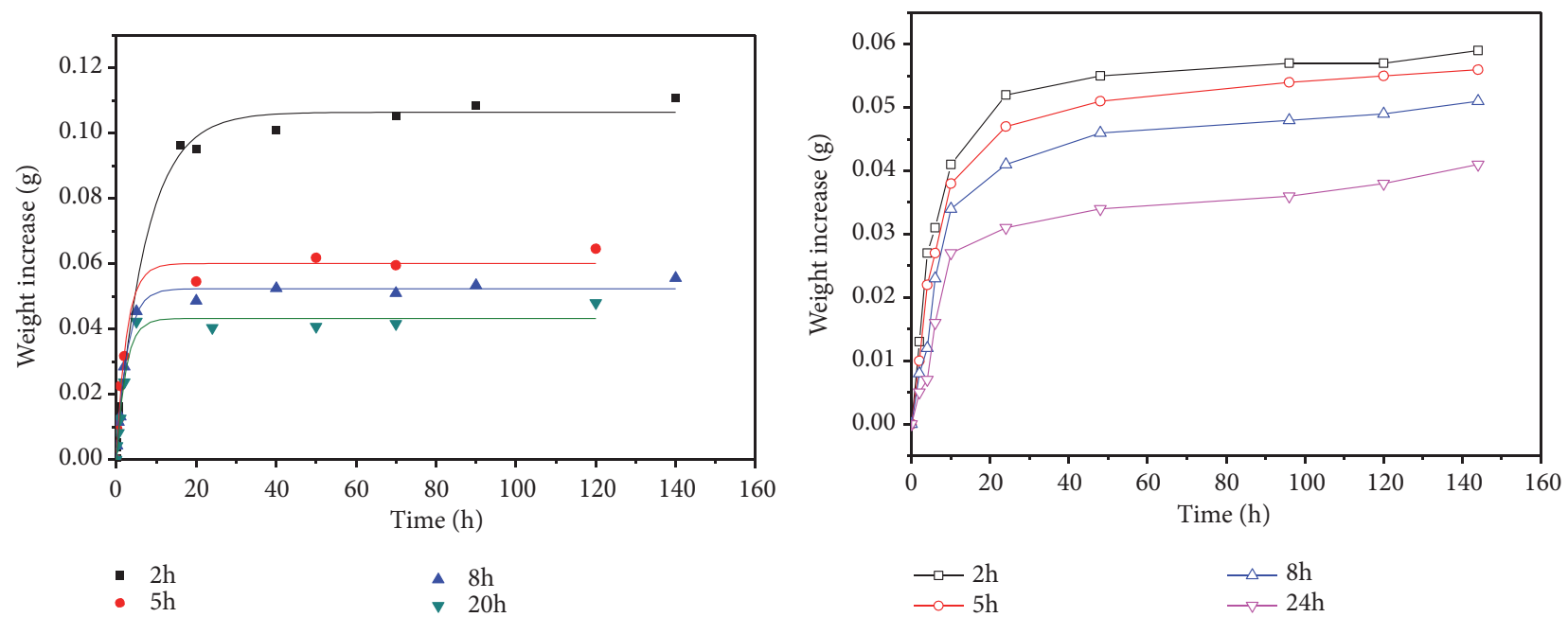

(a) Water-borne

(b) Solvent-based

FIgURE 5: The water absorption rates of the $\mathrm{P}(\mathrm{BA} / \mathrm{St})$ films for different formation times at room temperature. 
TABLE 3: The Russell-Routh model parameters* for the water-borne copolymer particles.

\begin{tabular}{ccccccc}
\hline & Temp. $/{ }^{\circ} \mathrm{C}$ & Hum. $/ \%$ & $\mathrm{~A} / \mathrm{m}^{2}$ & $\mathrm{H} / \mathrm{m}$ & $\bar{\lambda}$ & \multicolumn{1}{c}{ Pe } \\
\hline 1 & 35 & 60 & $4.8 \times 10^{-4}$ & $1.45 \times 10^{-4}$ & $1.73 \times 10^{-4}$ & 0.664 \\
2 & 30 & 60 & $4.8 \times 10^{-4}$ & $1.53 \times 10^{-4}$ & 0.473 \\
3 & 25 & 60 & $4.8 \times 10^{-4}$ & $1.52 \times 10^{-4}$ & $2.63 \times 10^{-4}$ & 0.463 \\
4 & 20 & 60 & $4.8 \times 10^{-4}$ & $1.63 \times 10^{-4}$ & $1.50 \times 10^{-2}$ & 0.463 \\
5 & 2 & 60 & $4.8 \times 10^{-4}$ & $1.72 \times 10^{-4}$ & $1.11 \times 10^{2}$ & 0.378 \\
\hline
\end{tabular}

* The Russell-Routh model parameters were calculated according to [22-24].
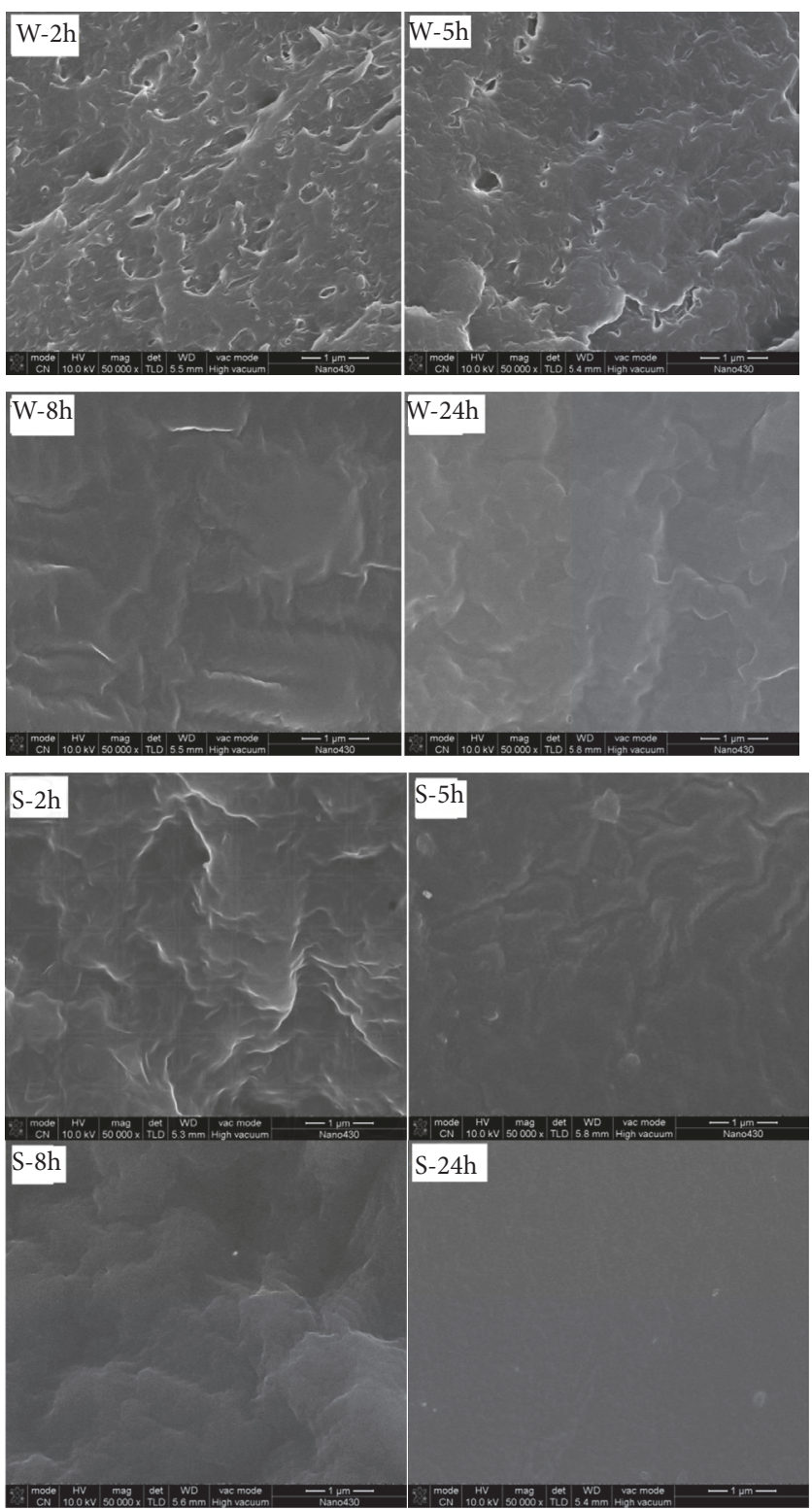

FIgURE 6: The microstructures of the films prepared with different film formation times.

films contained a large number of voids and a small amount of water remained in the film. However, the properties of the films improved for $1.0 \mathrm{~h}$. The film became uniform due to the diffusion of the copolymer from one particle to another particle. The resistance of the film was close to the resistance of the solvent-based copolymer in its dry film stage. For the solvent-based copolymer films, the EIS spectra showed that the resistance and barrier properties of the films also increased with film formation time. Initially, the solventbased films contained a small amount of solvent, and the 


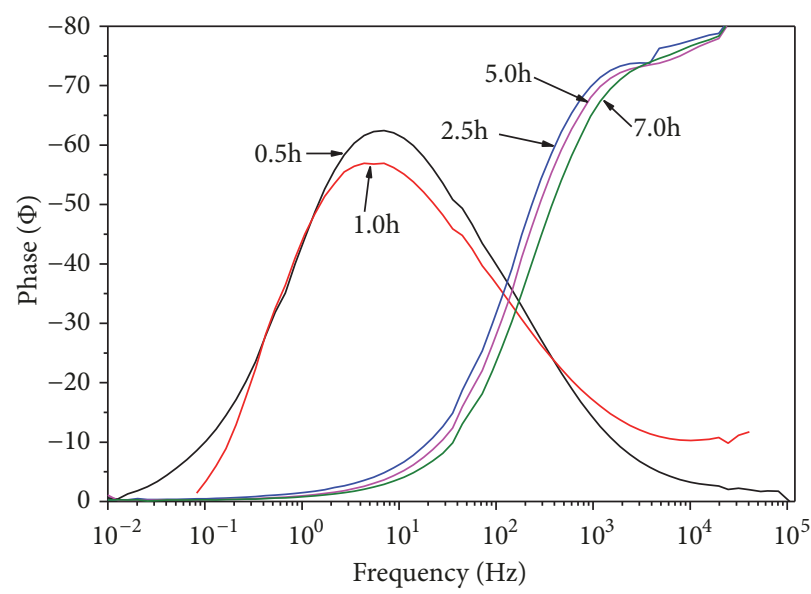

(a) Water-borne

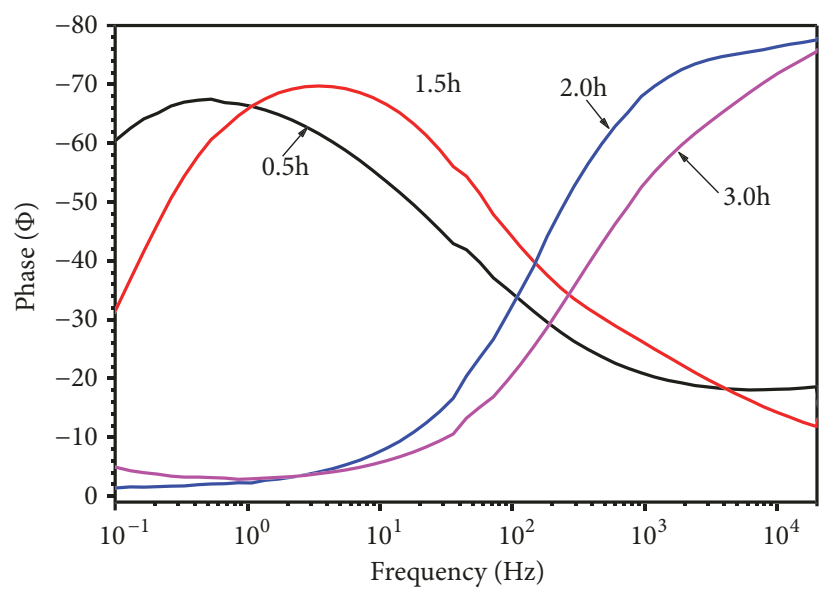

(c) Solvent-based

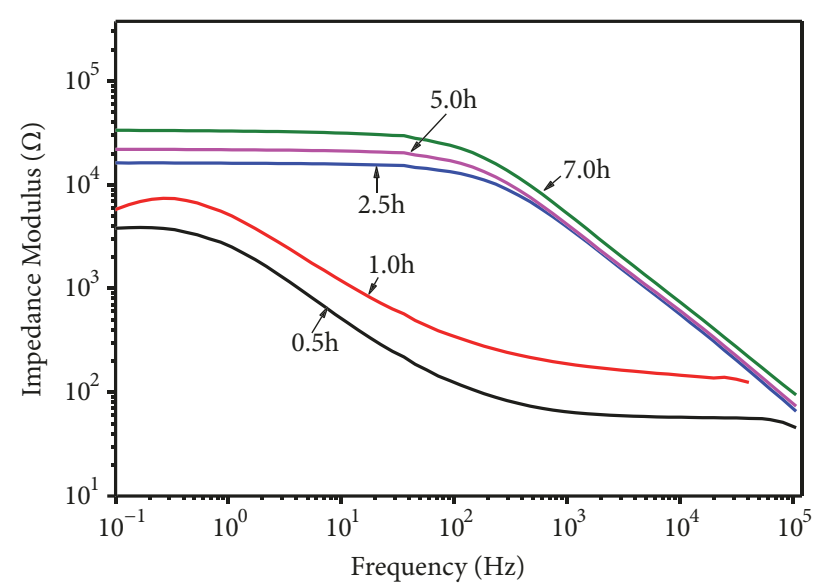

(b) Water-borne

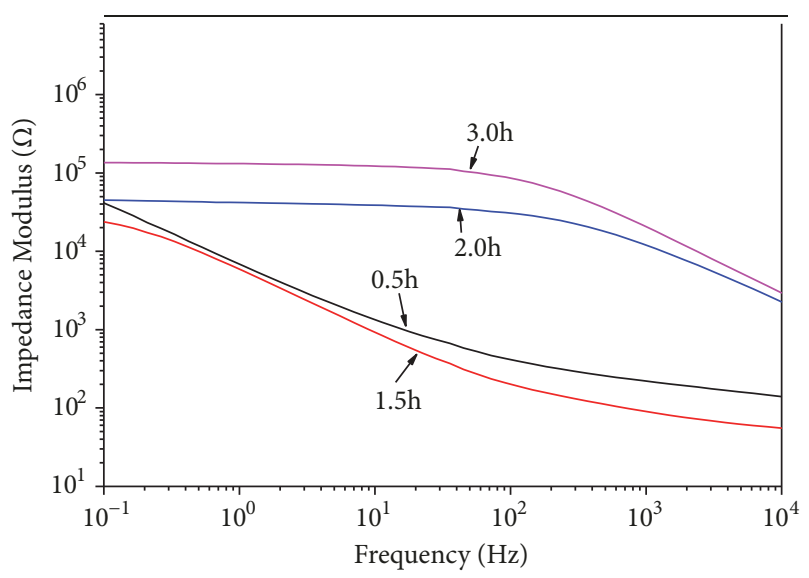

(d) Solvent-based

FIGURE 7: EIS Bode plots for films prepared with different formation times.

residual solvent would evaporate by diffusion to form a more compact film. Comparing the barrier properties of the waterborne and the solvent-based copolymer films, the two films had similar barrier properties and electrochemical features when their film formation times were sufficiently equal.

\section{Conclusions}

In conclusion, we synthesized a $\mathrm{P}(\mathrm{BA} / \mathrm{St})$ copolymer by two different methods and obtained the water-borne and the solvent-based copolymer systems with similar properties. The film formation processes of the two systems were studied and characterized. For the water-borne $\mathrm{P}(\mathrm{BA} / \mathrm{St})$ copolymer, the water evaporation process showed that the water evaporation rate during film formation of the copolymer was initially constant, but then the rate began to decrease and finally reached a rate of almost zero. During the film formation process, the copolymer particles deformed. The molecular diffusion occurred when water was present in the film. For the solvent-based $\mathrm{P}(\mathrm{BA} / \mathrm{St})$ copolymer, the evaporation process could be divided into two steps: one had a high evaporation rate and the other had a low evaporation rate.
Comparing the water-borne and the solvent-based films, the water absorption capacities of both films decreased with film formation times. When the film formation times were below $8 \mathrm{~h}$, the water-borne film could absorb more water than the solvent-based film. For film formation times over $8 \mathrm{~h}$, the two films absorbed almost the same mass of water. The water-borne films became more compact like the solventbased films, and the emulsifier became encapsulated by the copolymer. The water-borne and the solvent-based copolymers had film similar barrier properties and electrochemical features when the film formation time was extended.

However, in actual coating applications, the $\mathrm{Tg}$ of the polymer would change, and coalescent aids and additives could be used in the films. These additives would complicate the film formation mechanism. The film formation process and the complex properties of these films will be the subject of our future work.

\section{Data Availability}

The data used to support the findings of this study are available from the corresponding author upon request. 


\section{Disclosure}

Yi Wang was a Ph.D. candidate in material science at South China University of Technology in China. Professor Zhonghua Chen's research direction was polymer structure and properties at South China University of Technology in China.

\section{Conflicts of Interest}

The authors declare that they have no conflicts of interest.

\section{Acknowledgments}

This work was financially supported by the National Natural Science Foundation of China (21406073 and 50973033) and Guangzhou Jointas Chemical Co. Ltd. Thanks are due to Lin Fang for assistance with the experiments and Drs. Yu Fei to for valuable discussion.

\section{References}

[1] F. Lecomte, J. Siepmann, M. Walther, R. J. MacRae, and R. Bodmeier, "Polymer blends used for the coating of multiparticulates: comparison of aqueous and organic coating techniques," Pharmaceutical Research, vol. 21, no. 5, pp. 882-890, 2004.

[2] W. Yi, C. Zhonghua, and Y. Fei, "Coalescing aid influences on acrylic latexes property and film formation process," Indian Journal of Materials Science, vol. 2016, Article ID 1380791, 8 pages, 2016.

[3] A. Fortini, I. Martín-Fabiani, D. L. H. Jl, P. Y. Dugas, M. Lansalot, and F. D'Agosto, "Dynamic stratification in drying films of colloidal mixtures," Physical Review Letters, vol. 116, pp. 118301-118311, 2016.

[4] N. Swartz and T. L. Clare, "On the protective nature of wax coatings for culturally significant outdoor metalworks: microstructural flaws, oxidative changes, and barrier properties," Journal of the American Institute for Conservation, vol. 54, no. 3, pp. 181201, 2015.

[5] W. Li, T. Xu, C. Zhang, Z. Bao, and L. Chen, "Properties and characterization of novel cationic polyacrylate latex containing fluorine and silicon prepared with soap-free emulsion polymerization," Journal of Macromolecular Science, Part A Pure and Applied Chemistry, vol. 53, no. 2, pp. 104-110, 2016.

[6] S. Kara, Ö. Pekcan, A. Sarac, and E. Arda, "Film formation stages for poly(vinyl acetate) latex particles: a photon transmission study," Colloid and Polymer Science, vol. 284, no. 10, pp. 1097-1105, 2006.

[7] G. L. Brown, "Formation of films from polymer dispersions," Journal of Polymer Science, vol. 22, pp. 423-434, 1956.

[8] F. Lin and D. J. Meier, "A study of latex film formation by atomic force microscopy. 1. A comparison of wet and dry conditions," Langmuir, vol. 11, no. 7, pp. 2726-2733, 1995.

[9] F. Lin and D. J. Meier, "A study of latex film formation by atomic force microscopy. 2. Film formation vs rheological properties: Theory and experiment," Langmuir, vol. 12, no. 11, pp. 27742780, 1996.

[10] D. P. Sheetz, "Formation of films by drying of latex," Journal of Applied Polymer Science, vol. 9, no. 11, pp. 3759-3773, 1965.

[11] Y. Reyes-Mercado, F. Vázquez, F. J. Rodríguez-Gómez, and Y. Duda, "Effect of the acrylic acid content on the permeability and water uptake of poly(styrene-co-butyl acrylate) latex films," Colloid and Polymer Science, vol. 286, no. 5, pp. 603-609, 2008.

[12] T. F. Protzman and G. L. Brown, "An apparatus for the determination of the minimum film temperature of polymer emulsions," Journal of Applied Polymer Science, vol. 4, no. 10, pp. 81-85, 1960.

[13] S. Erkselius, L. Wadsö, and O. J. Karlsson, "Drying rate variations of latex dispersions due to salt induced skin formation," Journal of Colloid and Interface Science, vol. 317, no. 1, pp. 83-95, 2008.

[14] K. K. Price, A. V. McCormick, and L. F. Francis, "CryoSEM investigation of latex coatings dried in walled substrates," Langmuir, vol. 28, no. 28, pp. 10329-10333, 2012.

[15] O. Islam, K. I. Dragnevski, and C. R. Siviour, "On some aspects of latex drying-ESEM observations," Progress in Organic Coatings, vol. 75, no. 4, pp. 444-448, 2012.

[16] R. E. Trueman, E. Lago Domingues, S. N. Emmett, M. W. Murray, J. L. Keddie, and A. F. Routh, "Autostratification in drying colloidal dispersions: experimental investigations," Langmuir, vol. 28, no. 7, pp. 3420-3428, 2012.

[17] J. Park, H. Zheng, W. C. Lee, P. L. Geissler, E. Rabani, and A. P. Alivisatos, "Direct observation of nanoparticle superlattice formation by using liquid cell transmission electron microscopy," ACS Nano, vol. 6, no. 3, pp. 2078-2085, 2012.

[18] Ö. Pekcana, F. Kemeroglua, and E. Ardab, "Measuring backbone activation energy at polymer-polymer interfaces during latex film formation by using a photon transmission method," European Polymer Journal, vol. 34, no. 9, pp. 1371-1378, 1998.

[19] F. Belaroui, B. Cabane, M. Dorget, Y. Grohens, P. Marie, and Y. Holl, "Small-angle neutron scattering study of particle coalescence and SDS desorption during film formation from carboxylated acrylic latices," Journal of Colloid and Interface Science, vol. 262, no. 2, pp. 409-417, 2003.

[20] M. Soleimani, S. Khan, D. Mendenhall, W. Lau, and M. A. Winnik, "Effect of molecular weight distribution on polymer diffusion during film formation of two-component high-/lowmolecular weight latex particles," Polymer Journal, vol. 53, no. 13, pp. 2652-2663, 2012.

[21] M. S. Sunay, O. Pekcan, M. M. Rahman, A. Elaissari, and S. Ugur, "Spectroscopic study of film formation from polystyrene latex $/ \mathrm{TiO}_{2}$ nanocomposites prepared by dip-coating method," Polymer Engineering \& Science, vol. 54, no. 2, pp. 288-302, 2014.

[22] A. F. Routh and W. B. Russel, "Process model for latex film formation: Limiting regimes for individual driving forces," Langmuir, vol. 15, no. 22, pp. 7762-7773, 1999.

[23] J. L. Keddie and A. F. Routh, Fundamentals of Latex Film Formation, Springer, Netherlands, 2010.

[24] A. F. Routh, W. B. Russel, J. Tang, and M. S. El-Aasser, "Process model for latex film formation: optical clarity fronts," Journal of Coatings Technology, vol. 73, no. 916, pp. 41-48, 2001.

[25] J. Amalvy and D. Soria, "Vibrational spectroscopic study of distribution of sodium dodecyl sulfate in latex films," Progress in Organic Coatings, vol. 28, no. 4, pp. 279-283, 1996.

[26] S. Zohrehvand and K. te Nijenhuis, "Film formation from monodisperse acrylic lattices," Progress in Organic Coatings, vol. 55, no. 1, pp. 11-19, 2006.

[27] C. Le Pen, C. Lacabanne, and N. Pébère, "Characterisation of water-based coatings by electrochemical impedance spectroscopy," Progress in Organic Coatings, vol. 46, no. 2, pp. 77-83, 2003. 
[28] N. A. Swartz and T. L. Clare, "Understanding the differences in film formation mechanisms of two comparable solvent based and water-borne coatings on bronze substrates by electrochemical impedance spectroscopy," Electrochimica Acta, vol. 62, pp. 199-206, 2012.

[29] P. Berce, S. Skale, and M. Slemnik, "Electrochemical impedance spectroscopy study of waterborne coatings film formation," Progress in Organic Coatings, vol. 82, pp. 1-6, 2015.

[30] Y. Wang, Z. Chen, and F. Yu, "Preparation of epoxy-acrylic latex based on bisphenol F epoxy resin," Journal of Macromolecular Science, Part A Pure and Applied Chemistry, vol. 55, no. 2, pp. 205-212, 2018. 


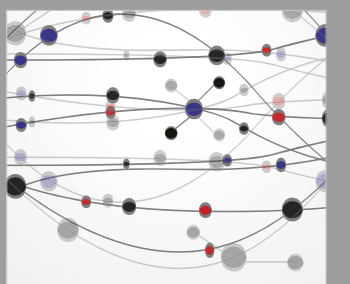

The Scientific World Journal
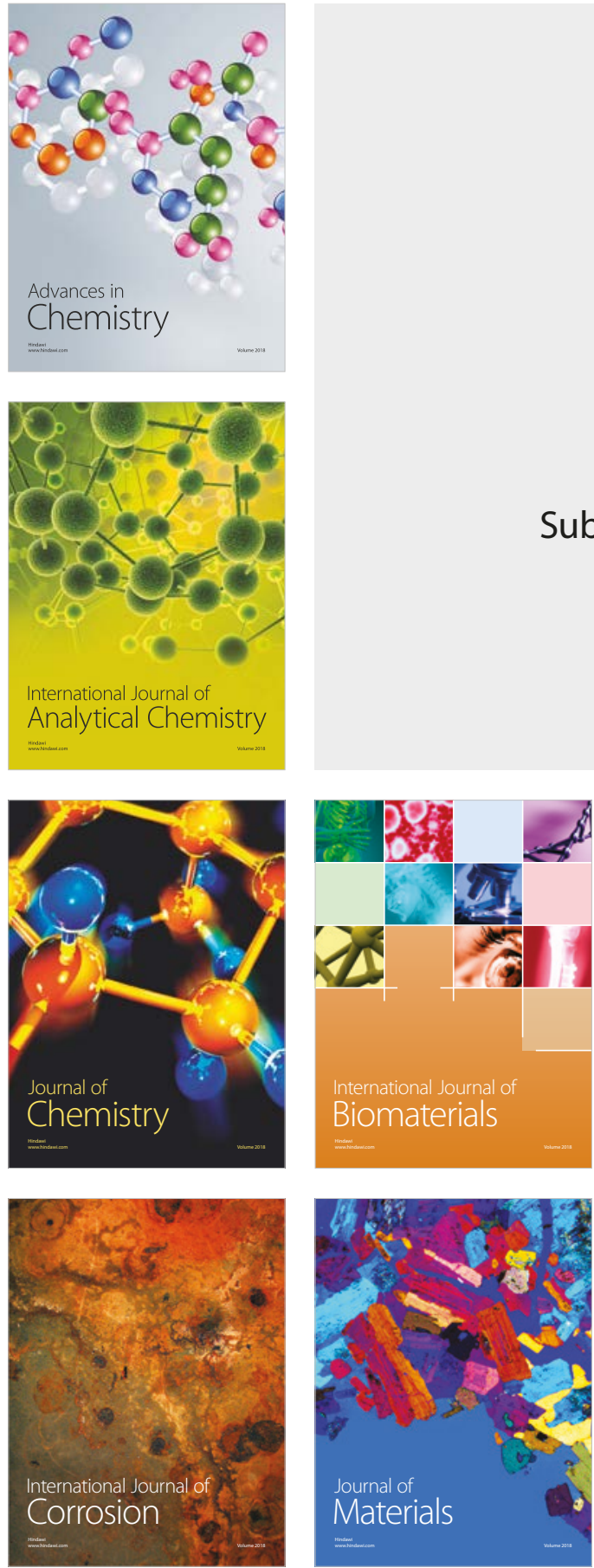

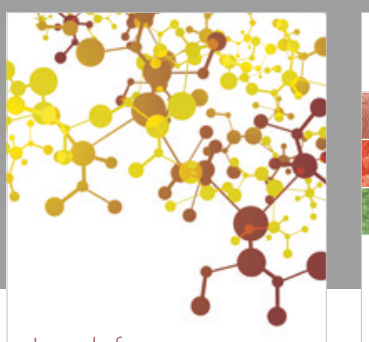

Journal of

Applied Chemistry
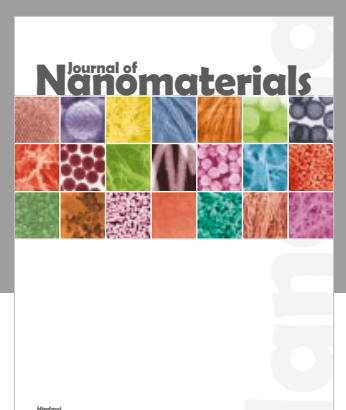

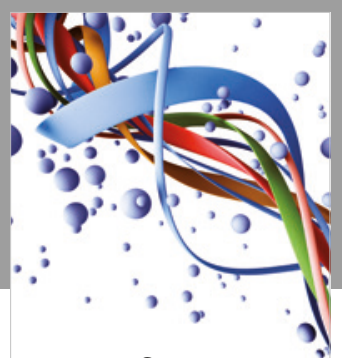

Scientifica

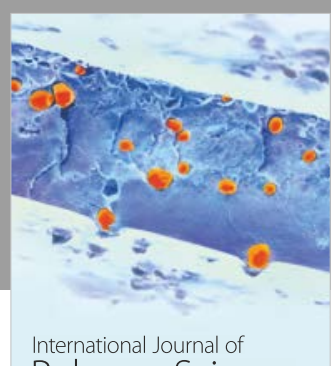

Polymer Science

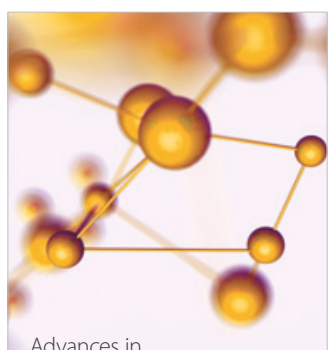

Physical Chemistry
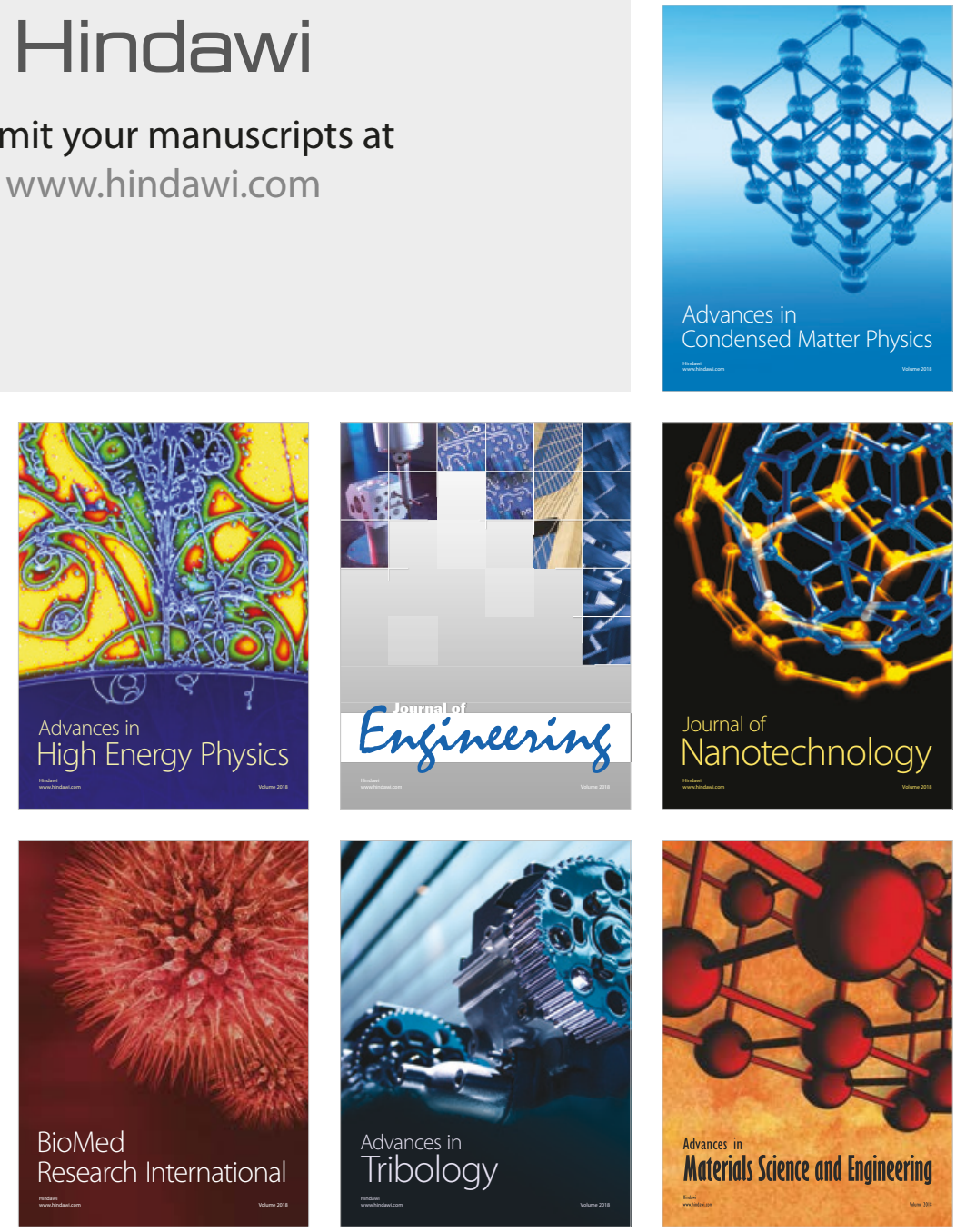